Article

\title{
Injection Treatment for Tunneling Excavation in Sandy Soils with High Fines Content
}

\author{
Johnatan González-García ${ }^{1}$ * , Celestino González-Nicieza ${ }^{2}$, Martina-Inmaculada Álvarez-Fernández ${ }^{2}$ (D) \\ and María-Belén Prendes-Gero ${ }^{2}$ (D) \\ 1 Perforaciones Noroeste, S.A., 33002 Oviedo, Spain \\ 2 DinRock Group, University of Oviedo, 33003 Oviedo, Spain; celestino@dinrock-uniovi.com (C.G.-N.); \\ inma@dinrock-uniovi.com (M.-I.Á.-F.); belen@dinrock-uniovi.com (M.-B.P.-G.) \\ * Correspondence: johnatan.gonzalez@perforacionesnoroeste.es
}

Citation: González-García, J.;

González-Nicieza, C.;

Álvarez-Fernández, M.-I.;

Prendes-Gero, M.-B. Injection Treatment for Tunneling Excavation in Sandy Soils with High Fines Content. Energies 2021, 14, 6930. https://doi.org/10.3390/en14216930

Academic Editor: Manoj Khandelwal

Received: 9 September 2021

Accepted: 20 October 2021

Published: 21 October 2021

Publisher's Note: MDPI stays neutral with regard to jurisdictional claims in published maps and institutional affiliations.

\begin{abstract}
Instability and high permeability are two of the problems facing tunnelling excavations in soils with high fines content. Among the different techniques used to improve these soils, the injection of cement grouts stands out. In this work, a grouting treatment is designed to ensure the stability of the ground during the construction of two tunnels linking two municipalities in the north of Spain in Biscay, and to reduce the inflow of water from the aquifer located in the vicinity of these tunnels. First of all, the rock mass is analysed and the material to be injected is selected on the basis of the authors' experience as well as setting time and compressive strength. Subsequently, with a test device designed by the DinRock research group of the University of Oviedo, two types of laboratory tests are carried out in order to analyse the effect of fines migration and washing on the water flows and the effect of re-injections of grouts with different densities on the permeability value. The results show that, in sandy materials, obtaining high degrees of waterproofing together with large stable zones can only be achieved by a combination of treatments and stages with different materials and densities. In addition, maximum values for both injection pressure and flow rate must be established depending on the type of grout and the permeability of the soil. Once the problem has been analysed, the injection treatment is designed and executed. The treatment consists of one pre-injection in four stages with 30 boreholes drilled in the top heading, 19-20 boreholes drilled in the bench, and one post-injection with boreholes drilled around the perimeter of the tunnel in those areas where the pre-injection does not achieve the desired degree of waterproofing.
\end{abstract}

Keywords: tunnelling excavation; injection treatment; cement grouting; ground stability; waterproofing

\section{Introduction}

Soil injections consist of filling inaccessible areas of the ground by introducing a fluid product made up of aqueous solutions of natural materials (cement or micro-cement grouts) and artificial materials through boreholes. These solutions improve the mechanical properties of the soil increasing the content of cement of the grouts [1], increasing the fines contents in decomposed granite soils [2], controlling deformations caused by underground construction [3], or preventing its liquefaction [4].

Other studies have analyzed the effect of grouting on increasing the strength of soils, ince grouting pressure not only affects the injectivity of grouts but also compacts and densifies the surrounding soil improving its behavior and geotechnical characteristics such as the pullout resistance $[5,6]$ or shear strength [7]. In practice, higher grouting pressure provides greater efficiency in improving ground settlement [8], increases the bearing capacity of the soil [9] and raises the strength per borehole in deep foundations [10].

One of the most important application of the grouting is in tunnel excavations. In this case, the main purpose of tunnel grouting is ground water ingress control, although sometimes improvement of ground stability represents another purpose. In tunnel grouting 
there are two fundamentally ways of working: pre-grouting or pre-excavation grouting [11] and post-grouting or post-excavation grouting [12]. At general, the post-grouting is employed when the pre-grouting is not enough to stop the ingress of water $[13,14]$. On the other hand, pressure injection has been successfully carried out in a range of rock formations, from weak sedimentary rocks $[15,16]$ to granitic gneisses, and has been used against very high hydrostatic head (up to $500 \mathrm{~m}$ water head) [17], as well as in shallow urban tunnels with low water head [18,19].

The selection of appropriate grouting material is an important step for the success of grouting. In tunnel injection the most employed material is the cement based grouts normally with additives such as accelerators or superplasticisers. The properties of cement grouts, such as rheology and flow behaviour, are controlled by the grain size and the water cement ratio $(\mathrm{w} / \mathrm{c})$ [20]. However, in the behaviour of cement grouts are very important the selection of grouting parameters, the method of grouting or the curing temperature [21,22].

Considering the grouting parameters, it is possible to say that the most important is the pressure of injection. In general, and for the same water/cement ratio $(\mathrm{w} / \mathrm{c})$, the injected grout volume increases almost linearly with the grouting pressure. However in sandy soils, an increase in the grouting pressure can produce fine migration and wash-out of the material increasing the permeability and the ingress of water [23].

Until relatively recently, this method was predominantly empirical, verifying its effectiveness with field extraction tests [24]. However, this type of testing can lead to errors when analyzing non-directly injected soils $[25,26]$, so real-time monitoring of the treatment is necessary [27].

In this work, a grouting treatment is designed to ensure ground stability during the construction of two tunnels linking two municipalities of the north of Spain in Biscay and to reduce water ingress from the aquifer located in the vicinity of these tunnels.

Once the problem to be solved has been described in the methodology section, the ground crossed is analyzed and the material to be injected is selected fundamentally on the basis of the setting time and compressive strength. Next, laboratory tests were carried out in order to explain the water flows observed as a consequence of a natural process of washing out the fines. In addition, progressive injection tests are carried with the end of analyzing the effect that successive injections of grouts with different densities have on the permeability value. All the tests have been carried out with a test device designed by the DinRock research group of the University of Oviedo.

Next, the injection treatment is described, which consists of a four-stage pre-injection in which the injected grout and/or its density is modified in each stage, and a postinjection to treat specific areas where the pre-injection does not achieve the desired degree of waterproofing.

Finally, after discussing some of the most problematic aspects in the design of the proposed injection treatment, the conclusions of the work are collected.

\section{Description of the Problem}

The construction of two tunnels (Figure 1) cross sandy soils and is very close to one aquifer. Due to this one, in the front advances, there is a greater flow of water towards the tunnel. This flow is so high that in the sections that cross the aquifer, the water table of this one is reduced affecting the supply of water of several towns and villages. Additionally, the inflow of water forces the works to stop due to the risks related to safety and the impact on the aquifer. Figure 2 shows, in red circles, filtration of water at the excavation face. 


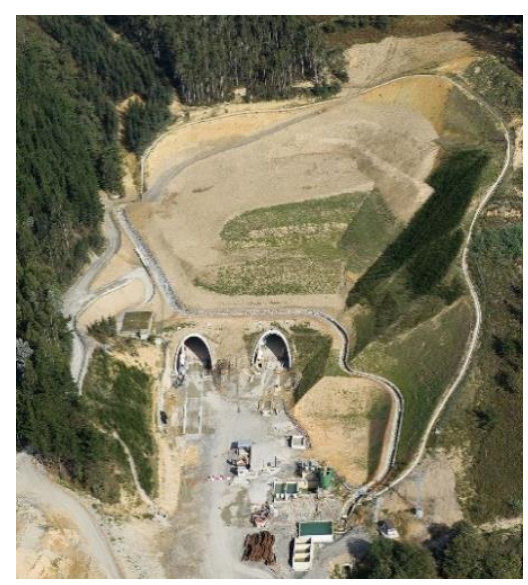

Figure 1. Tunnels under construction.

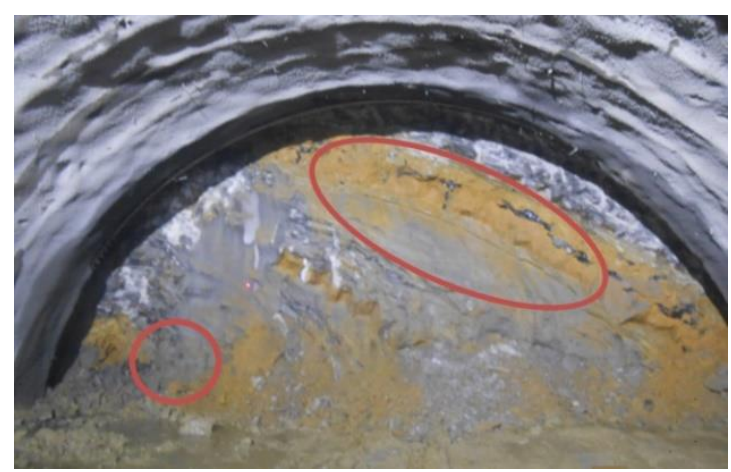

Figure 2. Water filtration at the front of the face.

Therefore, it is necessary to design an injection treatment of cement grout and/or microcement that not only improves the properties of the ground, ensuring the stability of the tunnel during construction, but also reduces the permeability to avoid water infiltration.

However, achieving greater waterproofing requires the filling of openings to the smallest possible size. This implies the use of very fine grouts with microcement, together with injection pressures as high as possible, to obtain maximum penetrability and a larger radius of reach. As the work progresses, it is observed that the inflow of water is greater than expected. To explain this phenomenon, it is hypothesized that the water filtration into the tunnel causes the migration of the finer fractions of the material, increasing the permeability of the ground in a progressive process of erosion. Besides, when the tunnel is excavated, a very marked gradient of hydraulic pressures is generated between the aquifer levels not yet affected by the excavation and the tunnel walls, where the fluid pressure is zero. This gradient generates an intense flow of water, with sufficient velocity to drag particles, in such a way that the excavation of the tunnel itself increases the permeability of the ground by washing it away.

Figure 3 shows the evolution of the pressure gradient.

- In the initial state, at the tunnel level, the hydrostatic pressure at a point is defined by (1).

$$
P=\rho \times g \times h
$$

where $P$ is the hydrostatic pressure, $\rho$ is the density of the fluid, $g$ is the acceleration of gravity, and $h$ is the height of the fluid.

- When a section of the tunnel is opened, the pressure on the roof is zero, while the pressure around the tunnel follows the expression of (1), generating a very high pressure gradient. This gradient causes a higher flow rate which facilitates the migration of the 
finer sands and, therefore, an increase in the permeability of the sands in the vicinity of the tunnel.

- Once most of the fine sands are migrated, the pressure gradient rises successively, which causes the sands at higher elevations to increase their permeability, leading to a progression of the phenomenon.

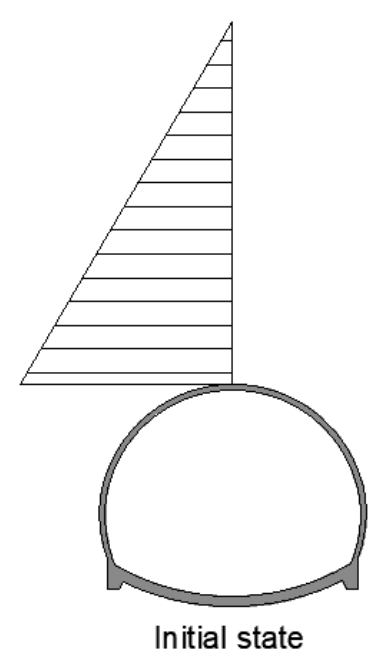

Figure 3. Evolution of the pressure gradient as the tunnel progresses.

Therefore, in addition to the need for soil improvement and waterproofing, there is also the problem of material migration, which increases the inflow of water and requires more intense and aggressive injection. However, a high injection pressure can cause an increase in pressure in certain areas of the aquifer, so that the hydraulic gradient available to generate these migrations can be increased by the injection process itself. Thus, the injection process should be controlled to avoid increasing the permeability of the aquifer in other areas by favoring the migration of fines.

\section{Methodology}

In order to carry out a correct design of the injection treatment, it is necessary to know both the material to be injected and the material where it is to be injected. To this end, a reconnaissance of the ground is carried out and the material to be injected is selected according to authors' experience and properties as exudation, setting or compressive strength. Next, the migration of fines is analyzed by means of laboratory tests using different proportions of soil granulometry and the influence that this migration has on the permeability of the tested soil is studied. Finally, and given that it is practically impossible to achieve a high degree of waterproofing in a single injection stage, a re-injection study is carried out using grouts of different densities.

\subsection{Recognition of the Rock Mass}

The rock mass in which the excavation is carried out belongs to the Lower Eocene and is formed by a fundamental series of shales, marls, and limestones, and a succession of sandstone, shale, and micro-conglomerate banks.

- In the first group of materials, the fundamental series consists of grey massive marls, grey leafy shales, somewhat micaceous, and micritic and massive limestones of a dark grey to blackish color with fine alternations of tabular banks. It is a material that is considered practically impermeable due to effective porosity and semi-permeable due to fracturing or surface alteration.

- The sandstone and microconglomerate banks are decametric to metric in thickness and alternate with impermeable shale levels. They consist of sandstones with a highly variable percentage of carbonate cement and a silty-clay matrix with a massive or 
finely laminated structure. Their permeability is high due to fissuring and alteration, but is also associated with a secondary porosity generated by washing and dissolution of calcareous cement, decomposing into sandy levels (sometimes coarse) with percentages of fines between 40 and $70 \%$. This high permeability is what causes the high water flows in the tunnel sections that cross the aquifer and the lowering of the water table of the aquifer.

\subsection{Selection of the Material to Be Injected}

Two standard cements are selected based on the authors' experience:

- Grouts of cement CEM II/B-M (V-L) 32.5R, with particle size less than 65 microns, Blaine grinding surface between 350 and $600 \mathrm{~m}^{2} / \mathrm{kg}$, and settlements of less than $4 \%$. In addition, superplasticising additives are used to increase fluidity and facilitate grouting, as well as accelerators to speed up setting. The $\mathrm{w} / \mathrm{c}$ ratios considered are between 0.5 and 0.7 and the most representative properties of the grouts are given in Table 1, including viscosity with the Marsh Cone [28], setting time and seven-day simple compressive strength.

Table 1. Characteristics of the cement grouts.

\begin{tabular}{cccccc}
\hline $\begin{array}{c}\text { w/c } \\
\text { Ratio }\end{array}$ & $\begin{array}{c}\text { Density } \\
\left(\mathbf{g} / \mathbf{c m}^{\mathbf{3}}\right)\end{array}$ & $\begin{array}{c}\text { Exudation } \\
\mathbf{( \% )} \mathbf{2} \mathbf{~ h}\end{array}$ & $\begin{array}{c}\text { Setting Time } \\
\mathbf{( h )}\end{array}$ & $\begin{array}{c}\text { Viscosity } \\
\mathbf{( s )}\end{array}$ & $\begin{array}{c}\text { Compressive } \\
\text { Strength } \mathbf{( M P a})\end{array}$ \\
\hline 0.5 & $1.62 \pm 0.1$ & $2.5 \pm 0.5$ & $3.0 \pm 0.20$ & $65 \pm 0.5$ & $30.7 \pm 2.0$ \\
0.6 & $1.61 \pm 0.1$ & $2.7 \pm 0.5$ & $3.5 \pm 0.20$ & $41 \pm 0.5$ & $24.6 \pm 1.8$ \\
0.7 & $1.59 \pm 0.1$ & $4.0 \pm 0.5$ & $4.5 \pm 0.35$ & $40 \pm 0.5$ & $17.9 \pm 1.6$ \\
\hline
\end{tabular}

- Microcement grouts with a penetrability superior to cement injections, a particle size less than 32 microns, a Blaine grinding surface greater than $1000 \mathrm{~m}^{2} / \mathrm{kg}$ and a w/c ratio of 1.5. To ensure that the fine particles of the microcement do not agglutinate and form larger clusters that reduce their penetration capacity, dispersants are added. In addition, and in order to avoid migration of the grout, it must have the shortest possible setting time. For the selection of the microcement, the properties of different commercial microcements such as wet bulk density, water exudation, setting time, viscosity with the Marsh Cone, and seven-day compressive strength are analysed. Table 2 shows the results of these analyses for two micro-cements with two maximum particle sizes (12 and 32 microns). The microcement with a particle size of 32 microns stands out, with lower viscosity and higher compressive strength. Therefore, this will be the microcement selected to carry out the injections.

Table 2. Characteristics of the microcement grouts.

\begin{tabular}{cccccc}
\hline $\begin{array}{c}\text { Micro- } \\
\text { cement }\end{array}$ & $\begin{array}{c}\text { Density } \\
\left(\mathbf{g} / \mathbf{c m}^{\mathbf{3}}\right)\end{array}$ & $\begin{array}{c}\text { Exudation } \\
\mathbf{( \% )} \mathbf{2} \mathbf{~ h}\end{array}$ & $\begin{array}{c}\text { Setting Time } \\
\mathbf{( h )}\end{array}$ & $\begin{array}{c}\text { Viscosity } \\
\mathbf{( s )}\end{array}$ & $\begin{array}{c}\text { Compressive } \\
\text { Strength (MPa) }\end{array}$ \\
\hline 12 & $1.36 \pm 0.1$ & $8 \pm 0.5$ & $18 \pm 1.0$ & $34 \pm 0.5$ & $23.7 \pm 2$ \\
32 & $1.35 \pm 0.1$ & $8 \pm 0.5$ & $5 \pm 0.5$ & $29 \pm 0.5$ & $25.0 \pm 2$ \\
\hline
\end{tabular}

\subsection{Laboratory Tests}

Once the different materials to be injected (cement CEM II/B-M (V-L) 32.5R and microcement 32) have been selected, the migration of fines produced in the excavated materials and their effect on permeability are analysed in order to verify the initial hypothesis.

Subsequently, in order to propose a methodology, medium-scale laboratory tests are carried out consisting of the progressive re-injection of the excavated material with grouts of different densities. The analyses are carried out with a test equipment designed by the DinRock research group of the University of Oviedo. 


\subsubsection{Test Equipment}

The test equipment allows testing saturated soils by injecting cement or microcement grouts at pressures up to $1.5 \mathrm{MPa}$, evaluating hydraulic properties before and after injection by continuously monitoring the pressure and flow rates injected, and visualizing the progression of the injected grouts (Figure 4).

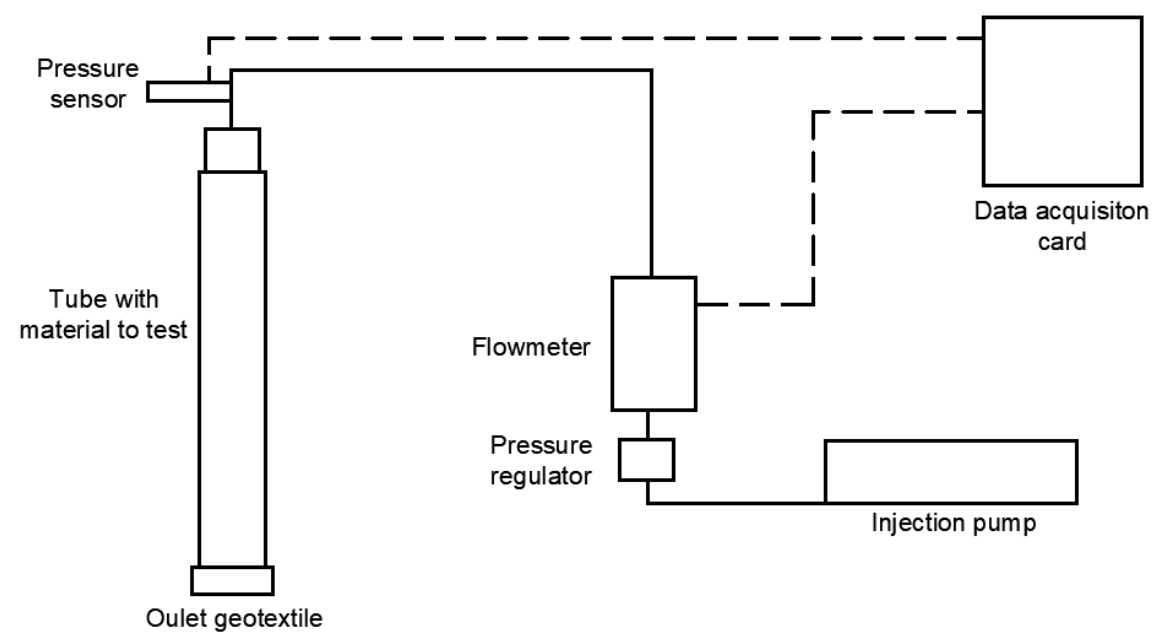

Figure 4. Simplified representation of the test equipment.

The main equipment designed for the test consists of:

- A transparent PVC glass tube, $90 \mathrm{~mm}$ in diameter and $1 \mathrm{~m}$ long. In its upper part, it has a head and a key that allows the tube to be connected to the injection circuit. At the bottom, it has a coupling that allows the insertion of a $150 \mathrm{~kg} / \mathrm{m}^{2}$ geotextile, which acts as a filter to prevent the material from leaving. The geotextile is placed between two custom-designed pieces manufactured using a 3D printer, which allow the geotextile to be perfectly fixed to the mouth of the tube (Figure 5);

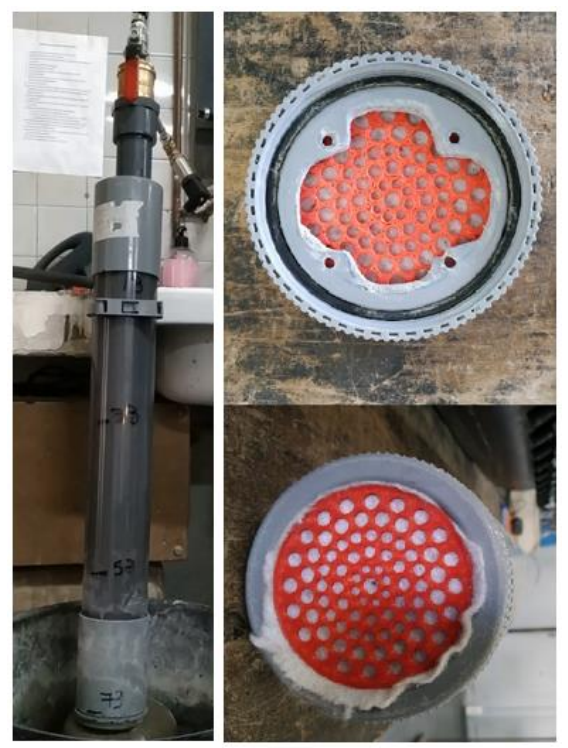

Figure 5. Left, PVC glass tube. Right, perforated and printed pieces.

- An IFM SM7000 magneto-inductive flowmeter, which can record flow rates from 0.2 to $30 \mathrm{~L} / \mathrm{min}$;

- A pressure sensor with a $2 \mathrm{MPa}$ full scale and a protective membrane, so that the grout does not come into direct contact with the sensor and damage it; 
- A pressure regulator which, by means of a screw, allows the circuit to be set to a fixed pressure over time;

- A Comet Systems MS6D Data Logger data acquisition card, which records the analogue signals from the different sensors every second, stores the data in its card memory and then downloads and exports them to an Excel file for further processing and analysis;

- An auxiliary circuit formed by the set of pipes and couplings that allows the correct assembly of all the aforementioned elements and the circulation of the fluids to be injected from the feeding point;

- A Desol PowerInject SP20 injection pump that supplies the fluid with energy, in the form of pressure, to circulate through the soil sample. It is a screw pump that allows a maximum pressure of $1.5 \mathrm{MPa}$, and a variable flow rate of $1.5-13.5 \mathrm{~L} / \mathrm{min}$.

\subsubsection{Analysis of Fines Migration and Washing}

In this test, the PVC tube of the equipment is placed horizontally with the material to be tested. The tube has two shut-off valves, one in the fluid inlet area and one in the outlet area. With both valves closed, the inlet valve is opened and water is allowed to enter up to a pressure of $0.5 \mathrm{MPa}$, which corresponds to a tunnel with a water column of about $50 \mathrm{~m}$ above it. After a few minutes, with the tube saturated, the outlet valve is opened allowing the water to flow out, which carries a part of the material that is collected, dried and weighed. Figure 6 shows the initial and final appearance of the sample, as well as the material that has been collected and dried in one of the tests carried out.
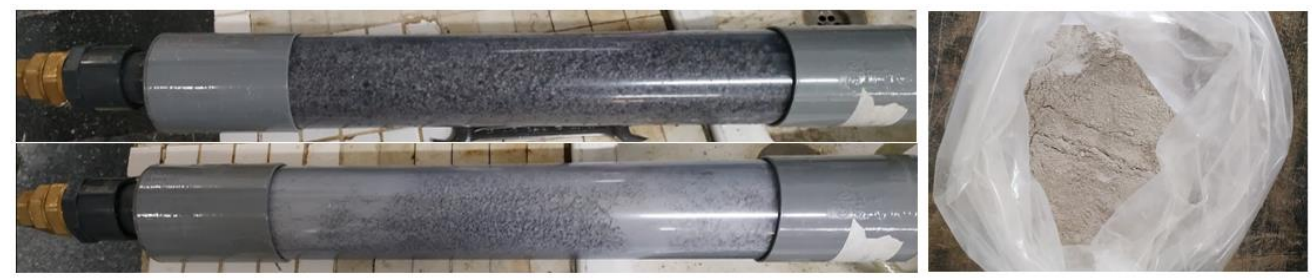

Figure 6. Initial and final appearance of the sample and extracted material.

In order to carry out the tests, the proportion of fines of the sand banks (40-70\%) has been taken into account. Four tests are carried out with a material created in the laboratory from the granulometric fractions of the original material (Table 3).

1. The first test is carried out with approximately $5 \mathrm{~kg}$ of soil composed of two different fractions ( $>2 \mathrm{~mm} ; 0.063-0.250 \mathrm{~mm}$ ). After a first washing, $0.537 \mathrm{~kg}$ of fine material are collected, i.e., $10.3 \%$ of the total material and $41 \%$ of the finer sands. A second wash is then carried out with the material still remaining in the tube, in which another 0.031 $\mathrm{kg}$ of fine material are collected. In other words, of the finest fraction introduced into the tube, $50 \%$ is migrated in just 2 min with a hydraulic gradient of $0.5 \mathrm{MPa}$ (Table 4 ).

2. In the second test, the coarser fraction $(>2 \mathrm{~mm})$ is replaced by a fraction with a smaller granulometry $(0.5-2 \mathrm{~mm})$. However, no migration is observed for hydraulic gradients of $0.5 \mathrm{MPa}$ and $0.9 \mathrm{MPa}$ (i.e., the initial permeability of these materials is so low that the flow rate cannot move the fines).

3. In the third test, the migration of an intermediate soil between the two previous tests is analysed and, its effect on permeability is studied. Four washes of 1 min each are carried out, subjecting the tube to a pressure of $0.5 \mathrm{MPa}$ between each wash. Table 5 shows that, of the fine fraction, $82.29 \%$ remains inside the tube, while the rest leaves with the outlet effluent.

4. A fourth test is carried out with the same granulometric fractions as in the previous test, but varying the percentages of these fractions. 4 washes of $1 \mathrm{~min}$ are carried out with hydraulic gradients of $0.5 \mathrm{MPa}$ between each wash. Table 6 shows that, of the fine fraction, $72.83 \%$ remains inside the tube while the rest is extracted in the outlet effluent. 
Table 3. Granulometric fractions and percentages of the samples tested (tolerance $\pm 5 \mathrm{~g}$ ).

\begin{tabular}{ccccc}
\hline Test & $\begin{array}{c}\text { Total Weight } \\
(\mathbf{k g})\end{array}$ & Granulometry $(\mathbf{m m})$ & Percentages $(\%)$ & $\begin{array}{c}\text { Fractions } \\
\mathbf{( k g})\end{array}$ \\
\hline \multirow{2}{*}{1} & 5.2 & $0.063-0.250$ & 25 & 1.302 \\
& & $>2$ & 75 & 3.906 \\
2 & \multirow{2}{*}{6.0} & $0.063-0.250$ & 25 & 1.5 \\
& & $0.5-2$ & 75 & 4.5 \\
3 & \multirow{2}{*}{6.0} & $0.063-0.25$ & 25 & 1.5 \\
& & $0.5-2$ & 50 & 3.0 \\
& & $>2$ & 25 & 1.5 \\
4 & \multirow{2}{*}{6.0} & $0.063-0.25$ & 25 & 1.5 \\
& & $0.5-2$ & 25 & 3.5 \\
& & $>2$ & 50 & 3.0 \\
\hline
\end{tabular}

Table 4. Summary of the results of the first test (tolerance of $\pm 5 \mathrm{~g}$ ).

\begin{tabular}{ccccc}
\hline & \multicolumn{2}{c}{ 1er Washing } & \multicolumn{2}{c}{$\mathbf{2}^{\circ}$ Washing } \\
& $\mathbf{~ k g}$ & $\mathbf{\%}$ & $\mathbf{~ k g}$ & $\mathbf{\%}$ \\
\hline Material that leaves & 0.537 & 41.32 & 0.031 & 2.38 \\
Material that remains & 4.671 & 58.68 & 4.640 & 56.30 \\
\hline
\end{tabular}

Table 5. Summary of the results of the third test (tolerance of $\pm 5 \mathrm{~g}$ ).

\begin{tabular}{ccccccccc}
\hline & \multicolumn{2}{c}{ 1er Washing } & \multicolumn{2}{c}{$\mathbf{2}^{\circ}$ Washing } & \multicolumn{2}{c}{ 3er Washing } & \multicolumn{2}{c}{$\mathbf{4}^{\circ}$ Washing } \\
& $\mathbf{k g}$ & $\mathbf{\%}$ & $\mathbf{k g}$ & $\mathbf{\%}$ & $\mathbf{k g}$ & $\mathbf{\%}$ & $\mathbf{k g}$ & $\mathbf{\%}$ \\
\hline Material that leaves & 0.006 & 0.43 & 0.005 & 3.94 & 0.127 & 8.49 & 0.073 & 4.84 \\
Material that remains & 5.994 & 99.57 & 5.987 & 95.63 & 5.860 & 87.14 & 5.787 & 82.29 \\
\hline
\end{tabular}

Table 6. Summary of the results of the fourth test (tolerance of $\pm 5 \mathrm{~g}$ ).

\begin{tabular}{ccccccccc}
\hline & \multicolumn{2}{c}{ 1er Washing } & \multicolumn{2}{c}{$\mathbf{2}^{\circ}$ Washing } & \multicolumn{2}{c}{ 3er Washing } & \multicolumn{2}{c}{$\mathbf{4}^{\circ}$ Washing } \\
& $\mathbf{k g}$ & $\mathbf{\%}$ & $\mathbf{k g}$ & $\mathbf{\%}$ & $\mathbf{k g}$ & $\mathbf{\%}$ & $\mathbf{k g}$ & $\mathbf{\%}$ \\
\hline Material that leaves & 0.019 & 1.26 & 0.011 & 7.69 & 0.252 & 16.80 & 0.021 & 1.41 \\
Material that remains & 5.981 & 99.98 & 5.969 & 91.05 & 5.718 & 74.25 & 5.696 & 72.83 \\
\hline
\end{tabular}

The evolution of permeability carried out on soils 3 and 4 (Table 7) shows the same behavior in both cases. A sharp increase in permeability between minutes 2 and 3 related to an increase in the mass of leaving fines. These results show that when more than two washings are carried out, the permeability of the treated sands increases and, therefore, the permeabilities of the areas to be injected can suffer large variations caused by the high-pressure injection of other areas of the tunnel. Close control of the injection pressure is therefore necessary to avoid migration of fine material and an increase in permeability. (The precision of the measures is of the order of one degree for the permeability, $0.05 \mathrm{~L}$ for the volume, and $0.005 \mathrm{~kg}$ for the weight of fines).

Table 7. Evolution of permeability in the third and fourth tests.

\begin{tabular}{ccccccc}
\hline & $\begin{array}{c}\text { Permeability } \\
(\mathbf{m} / \mathbf{s})\end{array}$ & $\begin{array}{c}\text { Test } 3 \\
\text { Volume } \\
(\mathbf{L})\end{array}$ & $\begin{array}{c}\text { Fines } \\
\mathbf{( k g )}\end{array}$ & $\begin{array}{c}\text { Permeability } \\
\mathbf{( m / s )}\end{array}$ & $\begin{array}{c}\text { Test 4 } \\
\text { Volume } \\
\mathbf{( L )}\end{array}$ & $\begin{array}{c}\text { Fines } \\
\mathbf{( k g )}\end{array}$ \\
\hline 1er Minute & $1.13 \times 10^{-5}$ & 0.21 & 0.006 & $2.29 \times 10^{-5}$ & 0.20 & 0.019 \\
$2^{\circ}$ Minute & $1.04 \times 10^{-5}$ & 0.20 & 0.005 & $1.42 \times 10^{-5}$ & 0.25 & 0.011 \\
3er Minute & $6.65 \times 10^{-4}$ & 11.91 & 0.127 & $1.05 \times 10^{-3}$ & 14.71 & 0.252 \\
$4^{\circ}$ Minute & $6.49 \times 10^{-4}$ & 11.86 & 0.073 & $1.06 \times 10^{-3}$ & 14.41 & 0.021 \\
\hline
\end{tabular}




\subsubsection{Analysis of Re-Injection}

In order to achieve the desired degree of waterproofing through grouting, it is common to work in stages, in other words, with re-injections, so that in the first stages the large cavities or fractures are closed and in later stages the small voids and/or fissures are closed. In each re-injection, either the density of the grout or the type of grout used is usually modified.

In the re-injection tests, the PVC tube is filled with the material to be tested. First, a cement grout with a w/c ratio of 0.5 is injected, and after setting $6 \mathrm{~h}$ the new porosity and permeability are analyzed. Next, a second grout of cement with a w/c ratio of 0.6 is injected on top of the material previously injected and again after $6 \mathrm{~h}$ setting the porosity and the permeability are analyzed. Finally, a grout with a w/c ratio of 0.7 is injected and the porosity and permeability are analyzed after $6 \mathrm{~h}$ of setting.

Table 8 shows the values of permeability, length of penetration of the grout, maximum pressure, and representative flow rate obtained in the re-injection tests carried out on the representative soil material. (The precision of the measures is of the order of one degree for the permeability, $0.01 \mathrm{~m}$ for the length of penetration and $0.5 \mathrm{~L} / \mathrm{min}$ for the flow).

Table 8. Re-injection test results.

\begin{tabular}{ccccc}
\hline Stage & $\begin{array}{c}\text { Permeability } \\
(\mathbf{m} / \mathbf{s})\end{array}$ & $\begin{array}{c}\text { Length of } \\
\text { Penetration }(\mathbf{m})\end{array}$ & $\begin{array}{c}\text { Maximum } \\
\text { Pressure }(\mathbf{M P a})\end{array}$ & $\begin{array}{c}\text { Flow rate } \\
(\mathbf{L} / \mathbf{m i n})\end{array}$ \\
\hline Initial & $7.7 \times 10^{-3}$ & - & - & - \\
Injection 0.5 & $9.5 \times 10^{-4}$ & 1.05 & $0.470 \pm 0.05$ & 10 \\
Injection 0.6 & $7.5 \times 10^{-5}$ & 0.60 & $1.160 \pm 0.1$ & 5 \\
Injection 0.7 & $3.2 \times 10^{-5}$ & 0.25 & $1.520 \pm 0.1$ & 2 \\
\hline
\end{tabular}

The table shows that in the second and third re-injection the penetration of the grout is less than $1 \mathrm{~m}$, and it is further reduced in the next re-injection. In addition, there is also a reduction in the permeability and in the flow rate in each of the stages, while the injection pressure increases.

\section{Proposed Solution}

Once the problem has been analyzed, an injection treatment is designed, consisting of two sub-treatments (one prior to the excavation of the tunnel and called pre-injection, and one after the excavation and placement of the tunnel support, called post-injection).

The aim of the pre-injection is to:

- Achieve a strip of "improved" ground with a minimum thickness of $3 \mathrm{~m}$ around the perimeter of the excavation to ensure the stability of the tunnel during its execution;

- Reduce the permeability until water infiltration from the tunnel does not exceed the maximum flow that can be withdrawn without significantly affecting the upper aquifer, which according to previous hydrological studies is $3 \mathrm{~L} / \mathrm{s}$.

With the post-injection is intended to treat specific areas where the pre-injection has not achieved the desired degree of waterproofing.

\subsection{Preinjection}

According to previous experiences and the tests carried out, a pre-injection with four stages of injection is designed. All of them with maximum pressures of $2 \mathrm{MPa}$, maximum flow rates of $15 \mathrm{~L} / \mathrm{min}$ and total injection admissions of $3 \%$ of the theoretical thickness treated. This pressure value, higher than three times the water pressure of the aquifer (1.7 MPa) but lower than the maximum that would produce large migration of fines (2.2 MPa), together with the injection in stages, allows to obtain a high degree of waterproofing at the same time that increase the geo-mechanical properties of the rock mass in two or three times their initial values. 
In the pre-injection, the boreholes are drilled with a diameter of $64 \mathrm{~mm}$ and a maximum length of $32 \mathrm{~m}$. But the action of gravity together with the irregularities of the ground, can cause deviations in the boreholes from 2 to $4 \%$ of the total drilled length, therefore, to ensure the minimum treatment thickness of $3 \mathrm{~m}$, the contour of the outermost boreholes is placed between 3 and $4.5 \mathrm{~m}$ away from the perimeter of the excavation, while the contour of the innermost boreholes is placed between 1 and $1.5 \mathrm{~m}$.

All of the boreholes are monitored in order to know, in real time, the pressure, the injection flow rate, and the volume of the grout injected. This control makes it possible to automate the end of the injection of each borehole, which in this case occurs when the maximum pressure value of $2 \mathrm{MPa}$ is reached and this value is maintained for 2 min with flow rates of no more than $3 \mathrm{~L} / \mathrm{min}$.

Figure 7a shows a longitudinal diagram of the boreholes of the four pre-injection stages, while Figure $7 \mathrm{~b}$ shows the process of injection of the boreholes in one of the four stages.

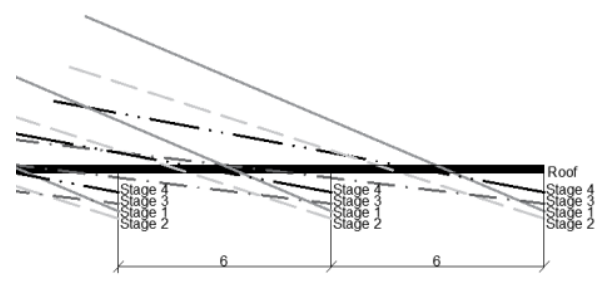

(a)

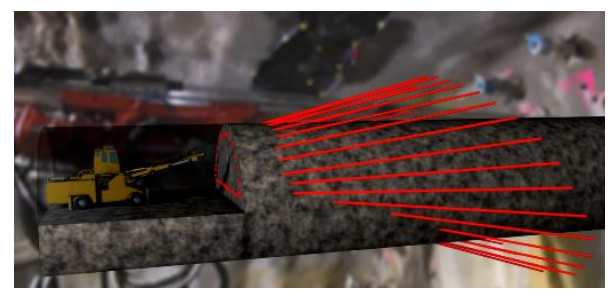

(b)

Figure 7. (a) Longitudinal diagram of the four pre-injection stages, (b) 3D representation of the process of injection.

\subsubsection{Stage 1 in the Top Heading}

Initially, eight boreholes, known as pilot boreholes, are drilled along the entire perimeter of the top heading excavation. The purpose of these boreholes is to determine the position and characteristics of the most permeable levels that will be intercepted by the treatment, but also to evaluate the flow rate.

The pilot boreholes are drilled and injected in successive phases of $6 \mathrm{~m}$ in length (i.e., once the $6 \mathrm{~m}$ length has been drilled and injected), the grout is left to set and the injected section is re-drilled until it reaches $12 \mathrm{~m}$ in length, which is again injected and left to set and then drilled again until it reaches $18 \mathrm{~m}$ and so on until the borehole length is completed.

Once the analysis of the pilot boreholes has been completed, the rest of the boreholes of this first injection stage are drilled. A total of 30 boreholes in the top heading and with a distance of $2 \mathrm{~m}$ between them ( 8 of them are the pilot boreholes). These boreholes are injected with a cement grout with a w/c ratio of 0.5 . The injection is carried out in a fan-shaped pattern starting with the bottom borehole, progressing upwards and alternating right and left.

The distribution of the 30 boreholes in the top heading including the 8 pilot boreholes (indicated with a P in brackets) is shown in Figure 8, while their geometrical properties are listed in Table 9. As can be seen in the figure, at this stage the outer contour of the boreholes is located at a distance of $4.5 \mathrm{~m}$ from the perimeter of the excavation. 


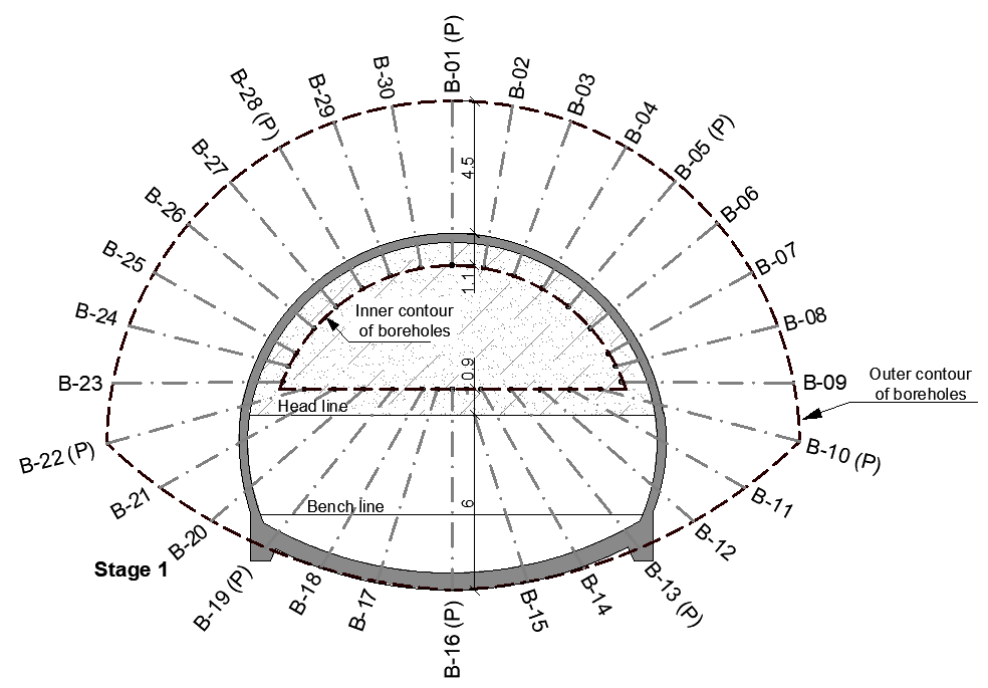

Figure 8. Drilling scheme of stage 1 in the top heading.

Table 9. Geometric properties of boreholes of stage 1 in the top heading (tolerance of $\pm 25 \mathrm{~cm}$ ).

\begin{tabular}{cccccccc}
\hline Number & $\begin{array}{c}\text { Length } \\
(\mathbf{m})\end{array}$ & $\begin{array}{c}\text { Azimuth } \\
\left(\mathbf{(}^{\mathbf{})}\right.\end{array}$ & $\begin{array}{c}\text { Inclination } \\
\mathbf{(}^{\circ} \mathbf{)}\end{array}$ & Number & $\begin{array}{c}\text { Length } \\
(\mathbf{m})\end{array}$ & $\begin{array}{c}\text { Azimuth } \\
\left.\mathbf{(}^{\circ}\right)\end{array}$ & $\begin{array}{c}\text { Inclination } \\
\left({ }^{\circ}\right)\end{array}$ \\
\hline B-01 & 16.09 & 0 & 23 & B-16 & 31.50 & 0 & -13 \\
B-02 & 15.23 & 3 & 22 & B-17 & 28.14 & -5 & -14 \\
B-03 & 16.65 & 6 & 19 & B-18 & 26.76 & -8 & -13 \\
B-04 & 18.33 & 9 & 15 & B-19 & 27.13 & -10 & -13 \\
B-05 & 22.21 & 10 & 12 & B-20 & 23.31 & -13 & -11 \\
B-06 & 22.25 & 11 & 9 & B-21 & 21.35 & -16 & -9 \\
B-07 & 24.37 & 11 & 7 & B-22 & 21.23 & -21 & -5 \\
B-08 & 26.52 & 12 & 3 & B-23 & 17.11 & -20 & 0 \\
B-09 & 28.64 & 11 & 0 & B-24 & 15.57 & -21 & 5 \\
B-10 & 31.50 & 12 & -3 & B-25 & 14.35 & -20 & 11 \\
B-11 & 31.04 & 10 & -6 & B-26 & 13.46 & -19 & 15 \\
B-12 & 31.42 & 9 & -8 & B-27 & 12.90 & -17 & 19 \\
B-13 & 31.50 & 7 & -10 & B-28 & 14.69 & -14 & 22 \\
B-14 & 31.27 & 6 & -12 & B-29 & 12.82 & -10 & 24 \\
B-15 & 30.70 & 3 & -13 & B-30 & 13.29 & -5 & 24 \\
\hline
\end{tabular}

Once the injection of stage 1 has been completed and in order to generate a waterproofing and stable zone in the part of the rock mass located in front of the surface of injection, 17 boreholes of $12 \mathrm{~m}$ in length are drilled and injected in the middle sections of the tunnel and 24 boreholes of $12 \mathrm{~m}$ in length are drilled and injected in the final sections of the tunnel (Figure 9, Table 10).
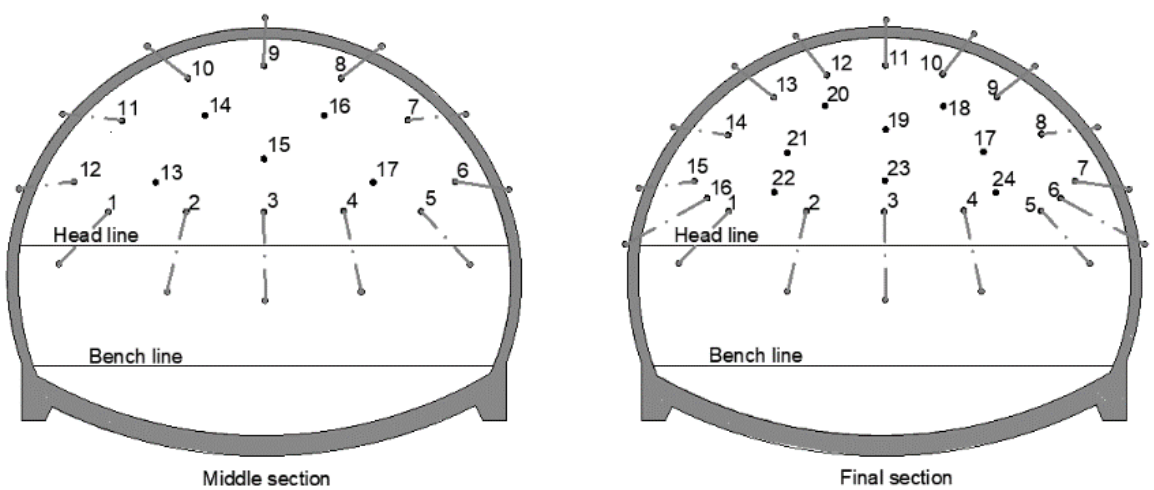

Figure 9. Drilling scheme of the consolidation boreholes in the top heading. 
Table 10. Geometric properties of the consolidation boreholes in the top heading (tolerance of $\pm 25 \mathrm{~cm})$.

\begin{tabular}{cccccc}
\hline Number & $\begin{array}{c}\text { Middle Section } \\
\text { Azimuth } \\
\left.\mathbf{(}^{\circ}\right)\end{array}$ & $\begin{array}{c}\text { Inclination } \\
\left.\mathbf{(}^{\circ}\right)\end{array}$ & Number & $\begin{array}{c}\text { Final Section } \\
\text { Azimuth } \\
\mathbf{(}^{\circ} \mathbf{)}\end{array}$ & $\begin{array}{c}\text { Inclination } \\
\left.\mathbf{(}^{\circ}\right)\end{array}$ \\
\hline 1 & -7 & -7 & 1 & -7 & -7 \\
2 & -3 & -11 & 2 & -3 & -12 \\
3 & 0 & -12 & 3 & 0 & -12 \\
4 & 3 & -11 & 4 & 3 & -11 \\
5 & 7 & -7 & 5 & 7 & -7 \\
6 & 7 & -1 & 6 & 11 & -6 \\
7 & 8 & 1 & 7 & 7 & -1 \\
8 & 6 & 4 & 8 & 7 & 1 \\
9 & 0 & 6 & 9 & 5 & 4 \\
10 & -6 & 4 & 10 & 4 & 5 \\
11 & -8 & 1 & 11 & 0 & 5 \\
12 & -7 & -1 & 12 & -4 & 4 \\
13 & 0 & 0 & 13 & -5 & 1 \\
14 & 0 & 0 & 14 & -7 & -1 \\
15 & 0 & 0 & 15 & -7 & -6 \\
16 & 0 & 0 & 16 & -11 & \\
\hline
\end{tabular}

These so-called face consolidation boreholes are sub-horizontal boreholes that create a volume of protection of the front with a truncated cone shape. They are injected with a cement grout with a $\mathrm{w} / \mathrm{c}$ ratio of 0.5 , alternating from bottom to top and alternating right and left.

\subsubsection{Stage 2 in the Top Heading}

As in the previous case, this stage has a total of 30 boreholes in the top heading (Table 11), which are injected with a cement grout with a w/c ratio of 0.6 and in a fan pattern, starting with the bottom borehole, progressing upwards, and alternating right and left. However, at this stage the distance between boreholes is less than in the first stage, around $1.2 \mathrm{~m}$, and the end of each borehole is $3 \mathrm{~m}$ from the perimeter of the excavation (Figure 10).

Table 11. Geometric properties of boreholes of stage 2 in the top heading (tolerance of $\pm 25 \mathrm{~cm}$ ).

\begin{tabular}{cccccccc}
\hline Number & $\begin{array}{c}\text { Length } \\
(\mathbf{m})\end{array}$ & $\begin{array}{c}\text { Azimuth } \\
\mathbf{(}^{\circ} \mathbf{)}\end{array}$ & $\begin{array}{c}\text { Inclination } \\
\mathbf{(}^{\circ} \mathbf{)}\end{array}$ & Number & $\begin{array}{c}\text { Length } \\
(\mathbf{m})\end{array}$ & $\begin{array}{c}\text { Azimuth } \\
\left.\mathbf{(}^{\circ}\right)\end{array}$ & $\begin{array}{c}\text { Inclination } \\
\left({ }^{\circ}\right)\end{array}$ \\
\hline B-01 & 14.09 & 0 & 18 & B-16 & 29.60 & 0 & -11 \\
B-02 & 15.23 & 2 & 16 & B-17 & 28.14 & -4 & -11 \\
B-03 & 16.65 & 4 & 14 & B-18 & 26.76 & -7 & -11 \\
B-04 & 18.33 & 7 & 12 & B-19 & 25.13 & -8 & -11 \\
B-05 & 20.21 & 8 & 10 & B-20 & 23.31 & -10 & -9 \\
B-06 & 22.25 & 9 & 7 & B-21 & 21.35 & -12 & -7 \\
B-07 & 24.37 & 9 & 6 & B-22 & 19.23 & -14 & -4 \\
B-08 & 26.52 & 9 & 2 & B-23 & 17.11 & -15 & 0 \\
B-09 & 28.64 & 9 & 0 & B-24 & 15.57 & -16 & 4 \\
B-10 & 30.85 & 10 & -3 & B-25 & 14.35 & -15 & 9 \\
B-11 & 31.04 & 9 & -5 & B-26 & 13.46 & -14 & 12 \\
B-12 & 31.42 & 8 & -7 & B-27 & 12.90 & -13 & 15 \\
B-13 & 31.50 & 6 & -9 & B-28 & 12.69 & -10 & 17 \\
B-14 & 31.27 & 5 & -10 & B-29 & 12.82 & -7 & 18 \\
B-15 & 30.70 & 2 & -11 & B-30 & 13.29 & -4 & 18 \\
\hline
\end{tabular}




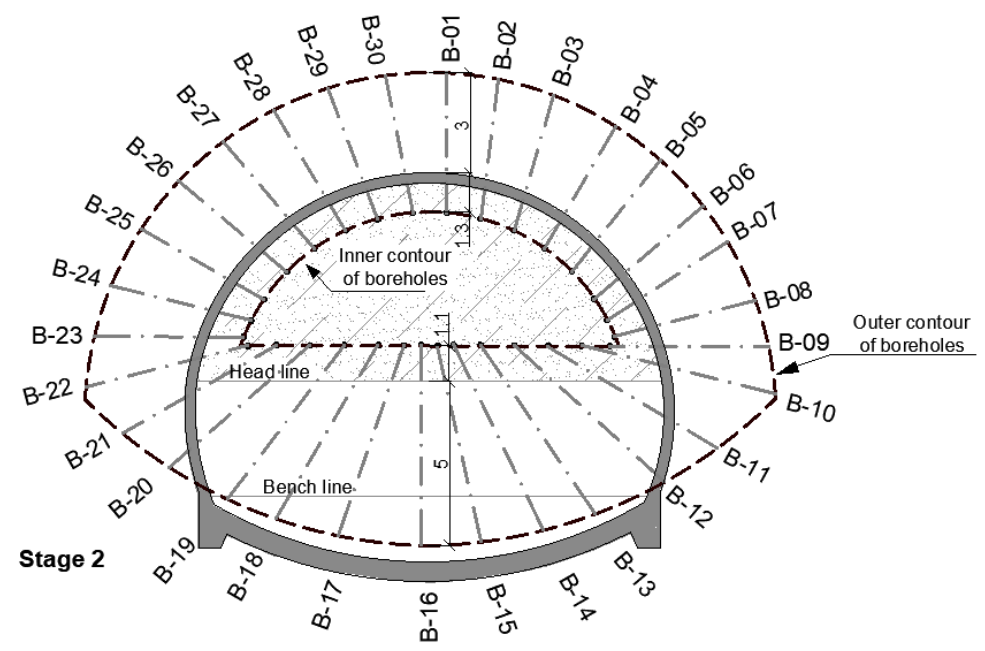

Figure 10. Drilling scheme of stage 2 in the top heading.

\subsubsection{Stage 3 in the Top Heading}

In this stage, 30 boreholes are drilled at a distance of $1.4 \mathrm{~m}$ between them and the outer contour of the boreholes is $1 \mathrm{~m}$ from the perimeter of the tunnel (Figure 11, Table 12).

Stage 3

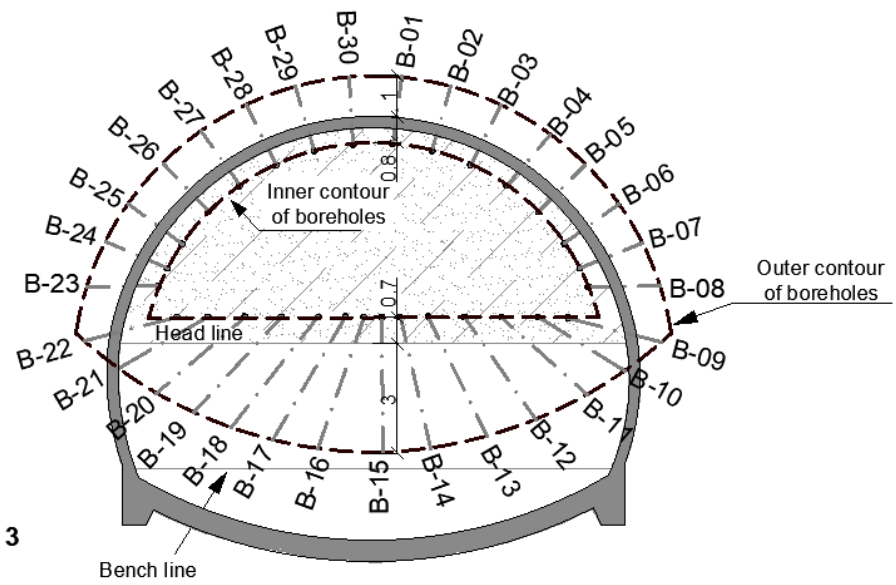

Figure 11. Drilling scheme of stage 3 in the top heading.

Table 12. Geometric properties of boreholes of stage 3 in the top heading (tolerance of $\pm 25 \mathrm{~cm}$ ).

\begin{tabular}{|c|c|c|c|c|c|c|c|}
\hline Number & $\begin{array}{l}\text { Length } \\
\text { (m) }\end{array}$ & $\begin{array}{c}\text { Azimuth } \\
\left({ }^{\circ}\right)\end{array}$ & $\begin{array}{c}\text { Inclination } \\
\left(\left(^{\circ}\right)\right.\end{array}$ & Number & $\begin{array}{l}\text { Length } \\
\text { (m) }\end{array}$ & $\begin{array}{l}\text { Azimuth } \\
\left({ }^{\circ}\right)\end{array}$ & $\begin{array}{c}\text { Inclination } \\
\left({ }^{\circ}\right)\end{array}$ \\
\hline B-01 & 14.09 & 1 & 7 & B-16 & 29.60 & -2 & -7 \\
\hline B-02 & 15.23 & 2 & 6 & B-17 & 28.14 & -4 & -7 \\
\hline B-03 & 16.65 & 3 & 5 & B-18 & 26.76 & -5 & -6 \\
\hline B-04 & 18.33 & 3 & 4 & B-19 & 25.13 & -5 & -6 \\
\hline B-05 & 20.21 & 3 & 3 & B-20 & 23.31 & -5 & -5 \\
\hline B-06 & 22.25 & 4 & 2 & B-21 & 21.35 & -6 & -3 \\
\hline B-07 & 24.37 & 4 & 1 & B-22 & 19.23 & -7 & -2 \\
\hline B-08 & 26.52 & 4 & 0 & B-23 & 17.11 & -6 & 0 \\
\hline B-09 & 28.64 & 4 & -1 & B-24 & 15.57 & -6 & 3 \\
\hline B-10 & 30.85 & 4 & -2 & B-25 & 14.35 & -6 & 4 \\
\hline B-11 & 31.04 & 4 & -4 & B-26 & 13.46 & -5 & 6 \\
\hline B-12 & 31.42 & 3 & -5 & B-27 & 12.90 & -5 & 6 \\
\hline B-13 & 31.50 & 3 & -6 & B-28 & 12.69 & -4 & 7 \\
\hline B-14 & 31.27 & 1 & -6 & B-29 & 12.82 & -2 & 8 \\
\hline B-15 & 30.70 & 0 & -7 & B-30 & 13.29 & -1 & 8 \\
\hline
\end{tabular}


In this case, the boreholes are injected in two phases, but the type of grout to be injected (cement or micro-cement) depends on the flow rate obtained in each borehole at the end of drilling. In this case, two situations can happen (Table 13).

Table 13. Grout injected in stage 3 as a function of the flow rate collected in each borehole.

\begin{tabular}{cccc}
\hline Case & Flow Rate (L/min) & Phase 1 & Phase 2 \\
\hline 1 & $>60$ & Cement (0.7) & Microcement (1.5) \\
2 & $<60$ & Microcement (1.5) \\
\hline
\end{tabular}

\subsubsection{Stage 4 in the Top Heading}

In this stage, 30 boreholes are drilled with a micro-cement grout with a $\mathrm{w} / \mathrm{c}$ ratio of 1.5 , a distance between them of $1.2 \mathrm{~m}$ and an outer contour of the boreholes of $2 \mathrm{~m}$ from the perimeter of the tunnel (Figure 12, Table 14).

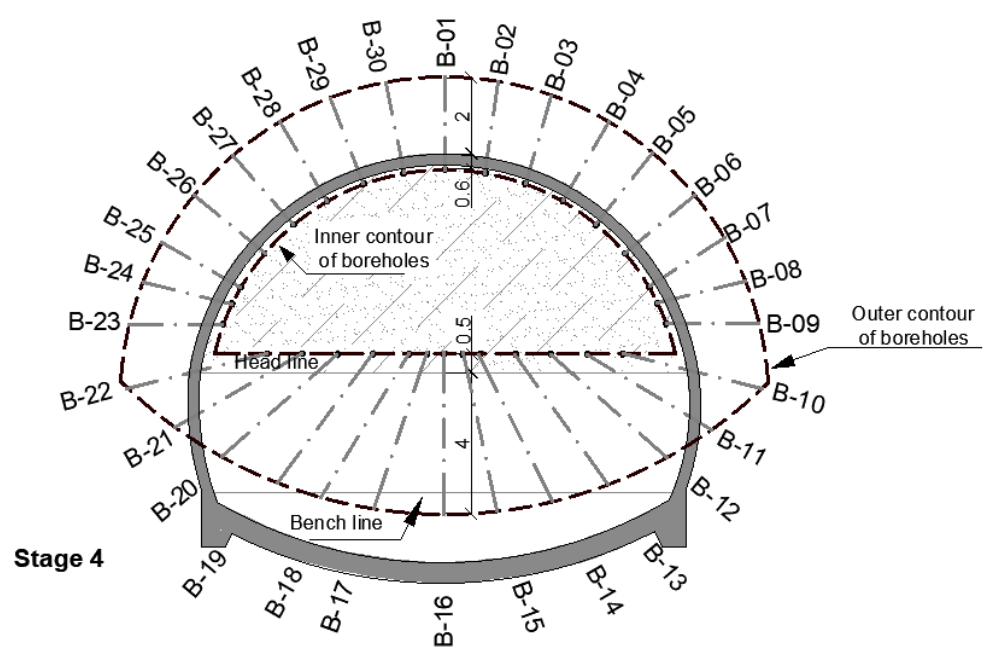

Figure 12. Drilling scheme of stage 4 in the top heading.

Table 14. Geometric properties of boreholes of stage 4 in the top heading (tolerance of $\pm 25 \mathrm{~cm}$ ).

\begin{tabular}{cccccccc}
\hline Number & $\begin{array}{c}\text { Length } \\
(\mathbf{m})\end{array}$ & $\begin{array}{c}\text { Azimuth } \\
\mathbf{(}^{\circ} \mathbf{)}\end{array}$ & $\begin{array}{c}\text { Inclination } \\
\left(\mathbf{(}^{\circ}\right)\end{array}$ & Number & $\begin{array}{c}\text { Length } \\
(\mathbf{m})\end{array}$ & $\begin{array}{c}\text { Azimuth } \\
\left({ }^{\circ}\right)\end{array}$ & $\begin{array}{c}\text { Inclination } \\
\left.\mathbf{(}^{\circ}\right)\end{array}$ \\
\hline B-01 & 14.09 & 0 & 11 & B-16 & 29.60 & 0 & -8 \\
B-02 & 15.23 & 1 & 10 & B-17 & 28.14 & -3 & -8 \\
B-03 & 16.65 & 3 & 9 & B-18 & 26.76 & -5 & -8 \\
B-04 & 18.33 & 4 & 7 & B-19 & 25.13 & -6 & -8 \\
B-05 & 20.21 & 5 & 6 & B-20 & 23.31 & -8 & -7 \\
B-06 & 22.25 & 5 & 4 & B-21 & 21.35 & -9 & -5 \\
B-07 & 24.37 & 5 & 3 & B-22 & 19.23 & -11 & -3 \\
B-08 & 26.52 & 5 & 1 & B-23 & 17.11 & -9 & 0 \\
B-09 & 28.64 & 5 & 0 & B-24 & 15.57 & -9 & 2 \\
B-10 & 30.85 & 7 & -2 & B-25 & 14.35 & -9 & 5 \\
B-11 & 31.04 & 6 & -4 & B-26 & 13.46 & -8 & 7 \\
B-12 & 31.42 & 6 & -5 & B-27 & 12.90 & -7 & 9 \\
B-13 & 31.50 & 4 & -6 & B-28 & 12.69 & -6 & 10 \\
B-14 & 31.27 & 4 & -7 & B-29 & 12.82 & -4 & 11 \\
B-15 & 30.70 & 2 & -8 & B-30 & 13.29 & -2 & 11 \\
\hline
\end{tabular}

As in stage 1, in this stage, eight control boreholes of $12 \mathrm{~m}$ in length are drilled, coinciding with boreholes 1, 5, 10, 13, 16, 19, 22 and 28 of the Figure 12.

\subsubsection{Pre-injection in Bench}

The bench pre-injection is similar to the top heading pre-injection with the difference that in this case the number of boreholes drilled are 19 for the first and fourth stages and 20 for the rest (Figure 13, Tables 15 and 16). 


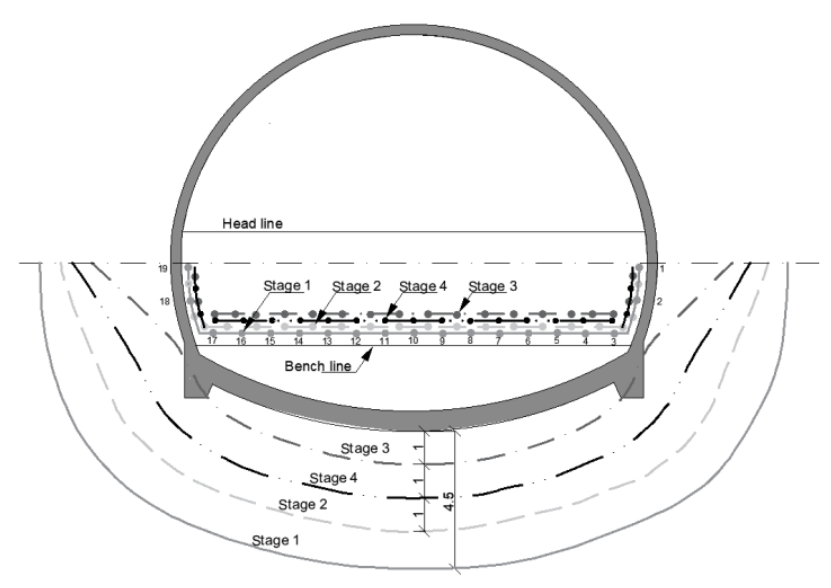

Figure 13. Outer contour boreholes in the bench excavation.

Table 15. Geometric properties of boreholes of stage 1 and 4 in the bench (tolerance of $\pm 25 \mathrm{~cm}$ ).

\begin{tabular}{|c|c|c|c|c|c|c|c|}
\hline \multicolumn{4}{|c|}{ Stage 1} & \multicolumn{4}{|c|}{ Stage 4} \\
\hline Number & $\begin{array}{l}\text { Length } \\
\text { (m) }\end{array}$ & $\begin{array}{l}\text { Azimuth } \\
\left({ }^{\circ}\right)\end{array}$ & $\begin{array}{c}\text { Inclination } \\
\left({ }^{\circ}\right)\end{array}$ & Number & $\begin{array}{l}\text { Length } \\
\text { (m) }\end{array}$ & $\begin{array}{l}\text { Azimuth } \\
\left({ }^{\circ}\right)\end{array}$ & $\begin{array}{c}\text { Inclination } \\
\left({ }^{\circ}\right)\end{array}$ \\
\hline 1 & 31.47 & 9 & 0 & 1 & 30.21 & 8 & 2 \\
\hline 2 & 29.48 & 10 & -1 & 2 & 28.72 & 8 & 2 \\
\hline 3 & 27.47 & 10 & -4 & 3 & 27.22 & 8 & 0 \\
\hline 4 & 25.51 & 11 & -8 & 4 & 25.84 & 9 & -3 \\
\hline 5 & 23.60 & 11 & -12 & 5 & 24.49 & 10 & -5 \\
\hline 6 & 21.90 & 9 & -15 & 6 & 23.14 & 11 & -8 \\
\hline 7 & 20.47 & 7 & -17 & 7 & 21.81 & 10 & -10 \\
\hline 8 & 19.25 & 5 & -19 & 8 & 20.53 & 9 & -12 \\
\hline 9 & 18.20 & 3 & -20 & 9 & 19.29 & 8 & -14 \\
\hline 10 & 17.28 & 0 & -21 & 10 & 18.12 & 6 & -15 \\
\hline 11 & 16.60 & -3 & -22 & 11 & 17.10 & 4 & -17 \\
\hline 12 & 16.48 & -6 & -22 & 12 & 16.22 & 1 & -18 \\
\hline 13 & 16.49 & -9 & -21 & 13 & 15.67 & -3 & -17 \\
\hline 14 & 16.63 & -12 & -19 & 14 & 15.40 & -6 & -15 \\
\hline 15 & 16.53 & -15 & -17 & 15 & 15.28 & -10 & -13 \\
\hline 16 & 16.45 & -17 & -13 & 16 & 15.56 & -12 & -9 \\
\hline 17 & 16.43 & -17 & -7 & 17 & 16.34 & -12 & -4 \\
\hline 18 & 17.78 & -15 & -2 & 18 & 17.44 & -12 & 0 \\
\hline 19 & 19.56 & -14 & 0 & 19 & 18.72 & -12 & 2 \\
\hline
\end{tabular}

Table 16. Geometric properties of boreholes of stage 2 and 3 in the bench (tolerance of $\pm 25 \mathrm{~cm}$ ).

\begin{tabular}{|c|c|c|c|c|c|c|c|}
\hline \multicolumn{4}{|c|}{ Stage 2} & \multicolumn{4}{|c|}{ Stage 3} \\
\hline Number & $\begin{array}{l}\text { Length } \\
\text { (m) }\end{array}$ & $\begin{array}{c}\text { Azimuth } \\
\left({ }^{\circ}\right)\end{array}$ & $\begin{array}{c}\text { Inclination } \\
\left({ }^{\circ}\right)\end{array}$ & Number & $\begin{array}{l}\text { Length } \\
\text { (m) }\end{array}$ & $\begin{array}{l}\text { Azimuth } \\
\left({ }^{\circ}\right)\end{array}$ & $\begin{array}{c}\text { Inclination } \\
\left({ }^{\circ}\right)\end{array}$ \\
\hline 1 & 30.11 & 7 & 2 & 1 & 30.11 & 7 & 2 \\
\hline 2 & 28.73 & 7 & 2 & 2 & 28.73 & 7 & 2 \\
\hline 3 & 27.41 & 7 & 1 & 3 & 27.41 & 7 & 1 \\
\hline 4 & 26.11 & 7 & -1 & 4 & 26.11 & 7 & -1 \\
\hline 5 & 24.86 & 8 & -3 & 5 & 24.86 & 8 & -3 \\
\hline 6 & 23.66 & 8 & -6 & 6 & 23.66 & 8 & -6 \\
\hline 7 & 22.48 & 9 & -8 & 7 & 22.48 & 9 & -8 \\
\hline 8 & 21.33 & 8 & -9 & 8 & 21.33 & 8 & -9 \\
\hline 9 & 20.22 & 8 & -11 & 9 & 20.22 & 8 & -11 \\
\hline 10 & 19.16 & 7 & -12 & 10 & 19.16 & 7 & -12 \\
\hline 11 & 18.18 & 5 & -13 & 11 & 18.18 & 5 & -13 \\
\hline 12 & 17.31 & 3 & -15 & 12 & 17.31 & 3 & -15 \\
\hline 13 & 16.55 & 1 & -16 & 13 & 16.55 & 1 & -16 \\
\hline 14 & 16.12 & -2 & -15 & 14 & 16.12 & -2 & -15 \\
\hline 15 & 15.92 & -4 & -13 & 15 & 15.92 & -4 & -13 \\
\hline 16 & 15.79 & -7 & -11 & 16 & 15.79 & -7 & -11 \\
\hline 17 & 16.11 & -9 & -7 & 17 & 16.11 & -9 & -7 \\
\hline 18 & 16.84 & -10 & -3 & 18 & 16.84 & -10 & -3 \\
\hline 19 & 17.74 & -10 & -1 & 19 & 17.74 & -10 & -1 \\
\hline 20 & 18.81 & -11 & 1 & 20 & 18.81 & -11 & 1 \\
\hline
\end{tabular}




\subsection{Post-Injection}

The post-injection is carried out in specific areas where it is necessary to increase the degree of waterproofing of the ground and always depending on the results obtained in the control boreholes of stage 4 . It is carried out by injecting microcement with a w/c ratio of 1.5 in boreholes distributed uniformly around the perimeter of the tunnel with a distance of $1.08 \mathrm{~m}$ between them and with a length of $10 \mathrm{~m}$ (Figure 14).

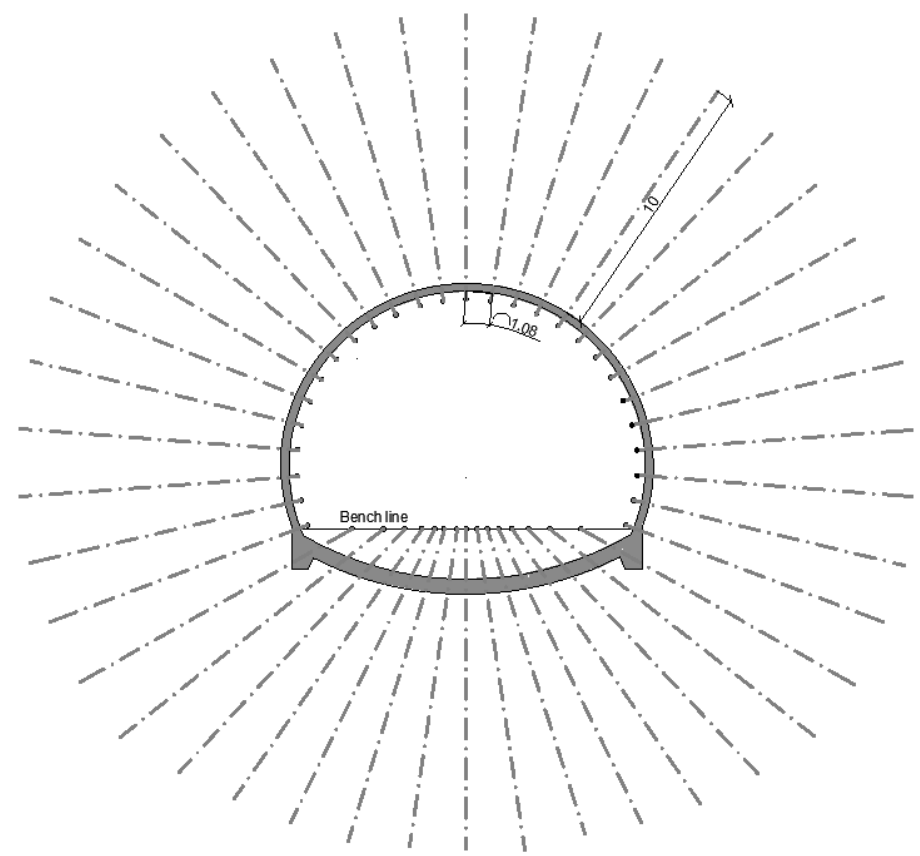

Figure 14. Drilling scheme of post-injection treatment.

\section{Discussions}

The construction of tunnels in grounds with low bearing capacity and high permeability can cause safety problems during the construction of the tunnel and even its subsequent collapse. In this case, and prior to the placement of the tunnel support, the use of face consolidation boreholes to create a volume of protection of the front is necessary.

On the other hand, the design of the tunnel support is based in the quality of the rock mass, but in sandy soils with such a low bearing capacity, together with high permeability, traditional supports are not enough since it is necessary to carry out soil consolidation actions at greater depths (which is achieved with pressure grouting treatments).

In these treatments, when the grounds traversed have large quantities of fines, these may migrate during the injection. This migration and the pressure gradient produced in the opening of the tunnels cause the opposite effect to the desired one. For that, it is very important to analyse the behaviour of the material to be injected by means of fine migration tests in order to limit the maximum injection pressure.

In addition, the degree of waterproofing required in this type of structure means that not only the larger holes but also the small cavities between the sandy particles must be closed. This objective is very difficult to acquire in a single injection, and it is necessary to work with injection treatments in stages using different grouts and different densities of the grouts in each stage. But a reduction in the permeability implies also a reduction in the penetrability, so it is essential to carry out prior re-injection tests that not only define the injection stages but also the borehole layout to ensure a uniform treatment and avoid the migration of fines.

However, due to the heterogeneity of the ground, the injection treatments must be flexible and checkpoints such as control boreholes must be defined. The checkpoints allow one, in real time, to evaluate the percentage of objectives achieved, modify the treatment if this percentage is lower than expected, and know if the ground conditions have changed 
and new tests are needed. In this case, having a simple and quick test device such as the one designed by de DinRock research group is essential.

At last, in the pressure grouting treatments, all boreholes must be monitored to know the injection pressure, the flow rate of injection, and the total volume of grout injected, avoiding the migration of fines and stablishing the end of injection in an automatic way.

This methodology has made it possible to solve such a complex problem as the construction of tunnels in sandy soils and under an aquifer, defining the borehole plan, the injection pressures and the injection stages. However, it should be tested in other cases and implemented in numerical models in order to optimise the process on site.

\section{Conclusions}

From the studies carried out, it can be said that:

- In waterproofing and stabilization of sandy soils with injection treatments, it is necessary to analyze the effect of high pressure injections in the migration of fines and the erosion of the surrounding ground $[29,30]$;

- High degrees of waterproofing together with large stable zones, are only achieved by a combination of treatments and stages using different materials and densities;

- The test equipment designed by the DinRock research group of the University of Oviedo allows to analyze the migration of fines due to high pressure injection and the effect that the re-injections with different densities of grout produce in the permeability of the ground;

- The test equipment allows to test the soil to be injected, analysing the penetrability for different grouts and their effect on the permeability, and optimizing the injection stages in each case;

- Although the injection of grouts, must be carried out at the highest possible injection pressures [29,30], the tests carried out limit the maximum pressure of injection in each stage depending on the different grouting conditions, as the type of grout and the permeability of the soil are successively modified;

- The limit of the maximum pressure together with the limit of the flow rate of injection requires a permanent monitoring of the injection process. Besides, this monitoring in real time allows to automate the stop of the injection;

- The designed injection treatment allows one to stabilize the ground and reduce the inflow of water employing one pre-injection in four stages with 30 boreholes drilled in the top heading and 19-20 boreholes drilled in the bench, and one post-injection with boreholes drilled around the perimeter of the tunnel in those areas where the pre-injection does not achieve the desired degree of waterproofing.

Author Contributions: Conceptualization, J.G.-G. and M.-I.Á.-F.; methodology, C.G.-N.; formal analysis, J.G.-G. and C.G.-N.; lab tests, M.-I.Á.-F. and M.-B.P.-G.; writing-original draft preparation, M.-B.P.-G.; writing —review and editing, M.-B.P.-G. and M.-I.Á.-F.; supervision, C.G.-N. All authors have read and agreed to the published version of the manuscript.

Funding: This research was funded by the Centre for the Development of Industrial Technology (CDTI) of the Science Ministry of the Spanish Government within the Research Project (IMPETU) grant number FUO-159-19.

Institutional Review Board Statement: Not applicable.

Informed Consent Statement: Informed consent was obtained from all subjects involved in the study.

Data Availability Statement: The data presented in this study are available on request from the corresponding author. The data are not publicly available due to confidentiality.

Acknowledgments: The authors want to acknowledge the Lurpelan Tunnelling S.A. company for the facilities provided for the development of the research.

Conflicts of Interest: The authors declare no conflict of interest. 


\section{References}

1. Dayakar, P.; Venkat-Raman, K.; Raju, K.V.B. Study on permeation grouting using cement grout in sandy soils. IOSR J. Mech. Civil. Eng. 2012, 4, 5-10. [CrossRef]

2. Wang, S.Y.; Chan, D.H.; Lam, K.C. Experimental study of the effect of fines content on dynamic compaction grouting in completely decomposed granite of Hong Kong. Constr. Build. Mater. 2009, 23, 1249-1264. [CrossRef]

3. Jafari, M.; Nasri, V.; Liu, J. Compensation grouting, laboratory and field investigations. In Geotechnical Engineering for Transportation Projects; American Society of Civil Engineers: Reston, VA, USA, 2004; pp. 1894-1904. [CrossRef]

4. Hamderi, M.; Gallagher, P.M. Pilot-scale modeling of colloidal silica delivery to liquefiable sands. Soils Found. 2015, 55, 143-153. [CrossRef]

5. Yin, J.H.; Su, L.J.; Cheung, R.W.M.; Shui, Y.K. The influence of grouting pressure on the pullout resistance of soil nails in compacted completely decomposed granite fill. Géotechnique 2009, 59, 103-113. [CrossRef]

6. Hong, C.Y.; Yin, J.H.; Pei, H.F.; Zhou, W.H. Experimental study on the pullout resistance of pressure-grouted soil nails in the field. Can. Geotech. J. 2013, 50, 693-704. [CrossRef]

7. Hossain, M.A.; Yin, J.H. Influence of grouting pressure on the behavior of an unsaturated soil-cement interface. J. Geotech Geoenviron. Eng. 2012, 138, 193-202. [CrossRef]

8. Bezuijen, A.; Van-Tol, A.F. Compensation grouting in sand, fractures and compaction. In Proceedings of the XIV European Conference on Soil Mechanics and Geotechnical Engineering, Rotterdam, The Netherlands, 24-27 September 2007; pp. 1257-1262.

9. Seo, H.J.; Jeong, K.H.; Choi, H.; Lee, I.N. Pullout resistance increase of soil nailing induced by pressurized grouting. J. Geotech. Geoenviron. Eng. 2012, 138, 604-613. [CrossRef]

10. Wannenmacher, H.; Wenner, D. Strategies of rock mass grouting for tunnel operations. In Proceedings of the 1st Regional and 8th Iranian Tunneling Conference, Tehran, Iran, 18 May 2009.

11. Garshol, K.F. Pre-Excavation Grouting in Tunneling; MBT, International Underground Construction Group: Zurich, Switzerland, 2003; p. 138.

12. Rollins, K.; Adsero, M.; Brown, D. Jet grouting to increase lateral resistance of pile group in soft clay. In Proceedings of the International Foundation Congress and Equipment Expo 2009, Orlando, FL, USA, 15-19 March 2009; pp. 265-272. [CrossRef]

13. Zhang, D.; Fang, Q.; Lou, H. Grouting techniques for the unfavorable geological conditions of Xiang'an subsea tunnel in China. J. Rock Mech. Geotech. Eng. 2014, 6, 438-446. [CrossRef]

14. Zou, L.; Håkansson, U.; Cvetkovic, V. Two-phase cement grout propagation in homogeneous water-saturated rock fractures. Int. J. Rock Mech. Min. Sci. 2018, 106, 243-249. [CrossRef]

15. Guatteri, G.; Koshima, A.; Lopes, J.R.; Ravaglia, A.; Pieroni, M.R. Historical cases and use of horizontal jet grouting solutions with $360^{\circ}$ distribution and frontal septum to consolidate very weak and saturated soils. In Proceedings of the 6th International Symposium Geotechnical Aspects of Underground Construction in Soft Ground, Shanghai, China, 10-12 April 2008.

16. Guatteri, G.; Koshima, A.; Lopes, R.; Ravaglia, A.; Pieroni, M.R.; Rocha, P.; Castanheira, M. Prototype tunnel in Barcelona-Test to check the construction feasibility with the $360^{\circ}$ horizontal jet grouting and frontal septum. In Proceedings of the 17th International Conference on Soil Mechanics and Geotechnical Engineering, Alexandria, Egypt, 5-8 October 2009. [CrossRef]

17. Blindheim, O.T.; Oevstedal, E. Design Principles and Construction Methods for Water Control in Subsea Road Tunnels in Rock; Norwegian Tunneling Society: Oslo, Norway, 2002.

18. Høien, A.; Nilsen, B. Rock mass grouting in the Løren Tunnel: Case study with the main focus on the groutability and feasibility of drill parameter interpretation. Rock Mech. Rock Eng. 2014, 47, 967-983. [CrossRef]

19. Guatteri, G.; Koshima, A.; Lopes, J.; Doro Altan, V. $360^{\circ}$ Jet grouted conical chamber allow safe tunneling under river within a highly pervious environment. In Proceedings of the GeEnge 2000-An International Conference on Geotechnical \& Geological Engineering, Melbourne, Australia, 19-24 November 2000.

20. Eriksson, M.; Friedrich, M.; Vorschulze, C. Variations in the rheology and penetrability of cement-based grouts-an experimental study. Cem. Concr. Res. 2004, 34, 1111-1119. [CrossRef]

21. Bohloli, B.; Skjølsvold, O.; Justnes, H.; Olsson, R.; Grøv, E.; Aarset, A. Cements for tunnel grouting-Rheology and flow properties tested at different temperatures. Tunn. Undergr. Space Technol. 2019, 91, 103011. [CrossRef]

22. Elkhadiri, I.; Palacios, M.; Puertas, F. Effect of curing temperature on cement hydration. Ceram. Silik. 2009, 53, 65-75.

23. Wang, Q.; Wang, S.; William-Sloan, S.; Sheng, D.; Pakzad, R. Experimental investigation of pressure grouting in sand. Soils Found. 2016, 56, 161-173. [CrossRef]

24. Pradhan, B.; Tham, L.G.; Yue, Z.Q.; Junaideen, S.M.; Lee, C.F. Soil-nail pullout interaction in loose fill materials. Int. J. Geomech. 2006, 6, 238-247. [CrossRef]

25. Paans, W.J.M. The Influence Zone and Effectiveness of Fracture Grouting on Piled Foundations. Ph.D. Thesis, TU Delft, Delft, The Netherlands, 2002.

26. Kolymbas, D. Tunnelling and Tunnel Mechanics: A Rational Approach to Tunnelling; Springer Science \& Business Media: Berlin/Heidelberg, Germany, 2005. [CrossRef]

27. Stille, B.; Stille, H.; Gustafson, G.; Kobayashi, S. Experience with the real time grouting control method. Geomech. Tunn. 2009, 2, 447-459. [CrossRef]

28. Spanish Association for Standardization and Certification. (AENOR). Paints and Varnishes—Determination of Flow Time by Use of Flow Cups (UNE-EN ISO 2431:2012.). Available online: https:/ / www.aenor.com/ (accessed on 17 May 2021). 
29. Sun, Z.; Yan, X.; Han, W.; Ma, G.; Zhang, Y. Simulating the Filtration Effects of Cement-Grout in Fractured Porous Media with the 3D Unified Pipe-Network Method. Processes 2019, 7, 46. [CrossRef]

30. Draganovi'c, A.; Stille, H. Filtration and penetrability of cement-based grout: Study performed with a short slot. Tunn. Undergr. Space Tech. 2011, 26, 548-559. [CrossRef] 